\title{
Aneurysmal Bone Cyst of the Zygomatic Arch Causing Limited Mouth Opening \\ CassBriogra
}

\begin{abstract}
Breno Souza Benevides ${ }^{1}$, José Maria Sampaio Menezes Junior², Marcelo Esmeraldo Holanda ${ }^{3}$, Fabrício Bitu Sousa ${ }^{4}$, Mariana Canuto Melo de Sousa Lopes ${ }^{4}$, Cauby Maia Chaves Junior ${ }^{5}$, Hermes Melo Teixeira Batista ${ }^{6}$, Bruno Souza Benevides ${ }^{7}$
\end{abstract}

\section{Abstract}

The Aneurysmal Bone Cyst $(A B C)$ is an expansive osteolytic, radiolucent, multilocular, eccentric lesion of unknown origin consisting of spaces filled with blood in any segment of the skeleton, being most frequently encountered in the diaphysis of the long bones or the spinal cord. It may occur as distinct clinico-pathological entity or as pathophysiological alteration of a preexisting lesion, like giant-cells lesion, fibrous dysplasia, ossifying fibroma, osteoblastoma, epiphysary chondroblastoma and even malignant lesions such as osteossarcoma. This paper reports a rare case of $A B C$ in the zygomatic arch of a young female patient who presented facial asymmetry and progressive limitation in mouth opening, treated by resective surgical procedure and discusses the clinical, radiological and histological features of this pathology along with its treatment.

\section{Keywords}

Bone cysts, aneurysmal, zygoma

\section{Introduction}

Aneurysmal Bone Cyst $(A B C)$ is a clinicopathological entity described in the literature [1], which etiology and etiopathogenesis are unknown. There is also controversy about its nomenclature, because this lesion is not a vascular aneurysm and also not an osseous cystic lesion [2]. The histological findings reveal giant cells surrounded by a fibrous connective tissue, varied amounts of bone and reactional osteoid tissue, numerous cavities or blood sinusoids without epithelial or endothelial coating $[3,4]$. 
$A B C$ commonly affects the metaphyseal region of long bones, pelvis or vertebral column. It presents as an eccentric tumor that insufflates the cortical bone and by its growth destroys the metaphysealepiphyseal region. $A B C$ occurs more commonly in females in their second-decade [5]. Only $2 \%$ of all $A B C$ literature related cases are on the head and neck region [6] and represent $1.5 \%$ of all non-odontogenic cysts of jaws [7]. In these cases, mandible is the most affected bone, followed by maxilla (3:1). Zygomatic bone is rarely involved [3, 4]. The radiological findings of this lesion are not unique and, therefore, not pathognomonical [4].

Clinical evolution of $A B C$ varies from a lesion showing self-limited slow-growth pattern to an aggressive lesion showing rapid destructive behavior, such as the malignant neoplasic tumors [8]. Treatment of choice is complete surgical removal. This may be difficult in cases of extensive multiloculated lesions. Therefore, some treatment alternatives were proposed: lesional resection with or without bone grafting, curettage with or without cryotherapy or bone grafting, arterial embolization followed by surgical excision [9]. Intralesional corticostheroid, calcitonin injection or radiotherapy (RT) can be used as a unique treatment or as an adjuvant treatment (10). Whenever recurrence is present, it is due to inadequate removal of the lesion approach and/or incomplete resection $[3,4]$.

\section{Case report}

A 14 year-old female patient was referred to dental care due to progressively growing hard asymptomatic swelling on the face in the middle third region. The patient also had a progressively decreasing mouth opening for the past 5 months (figures 1 and 2).

Clinical examination revealed facial asymmetry and local swelling of the left zygomatic arch, normal overlying skin and $32 \mathrm{~mm}$ interincisal mouth opening. Computed Tomography (CT) showed an expansive hypodense lesion of $4 \mathrm{~cm} \times 2 \mathrm{~cm}$ in size

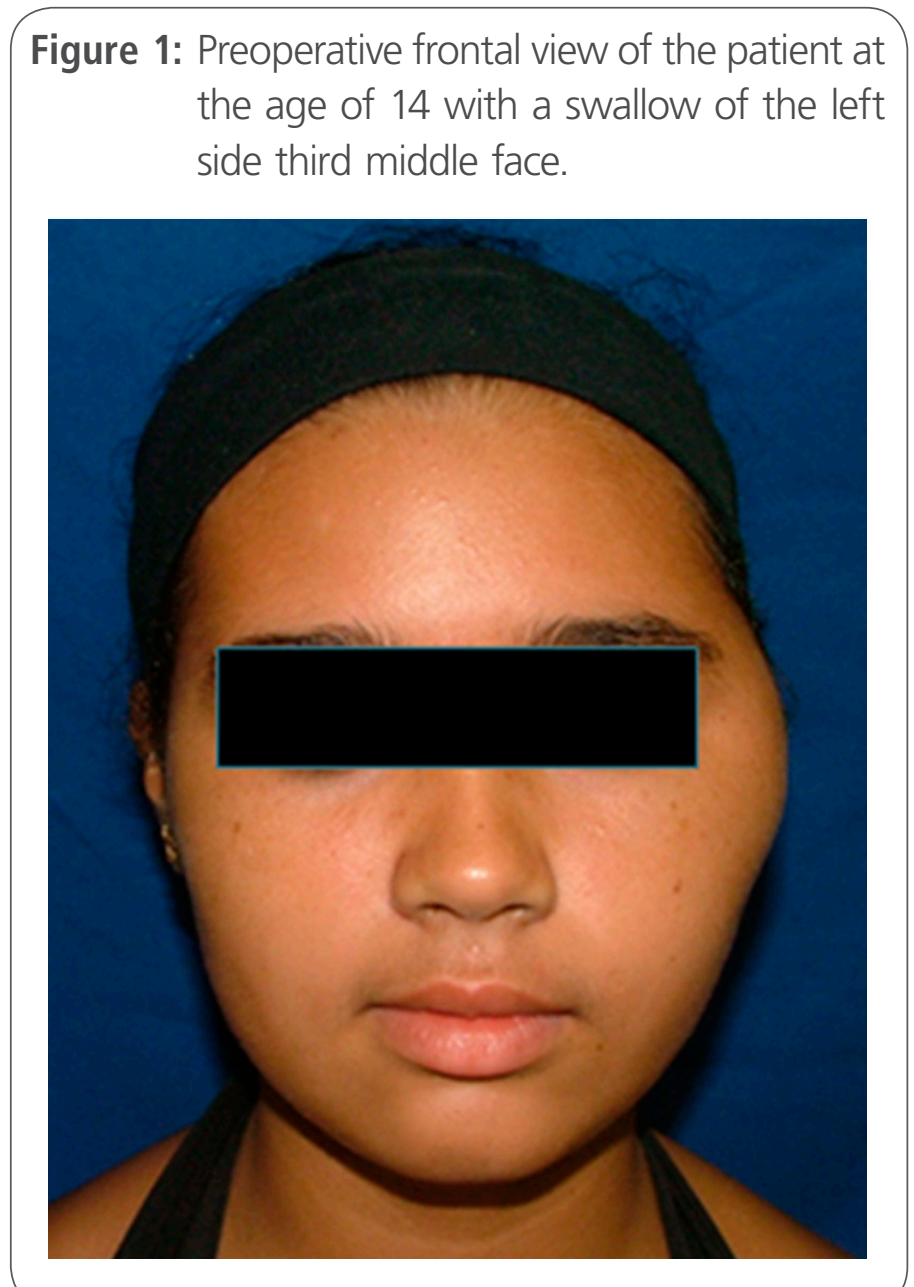

Figure 2: Preoperative view, showing a $32 \mathrm{~mm}$ limited mouth opening.

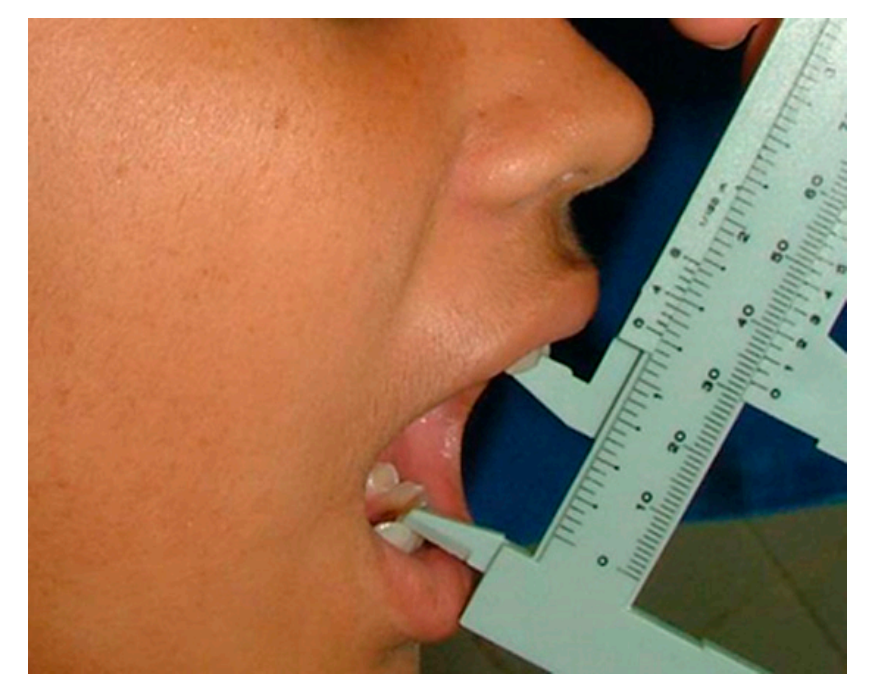


with a discontinuous hyperdense lining and discrete hyperdense loculation in its interior (figure 3). This lesion expanded the entire left zygomatic arch and showed a close anatomic relationship to the ispilateral coronoid process of the mandible, which was probably the etiologic factor for the progressive limited mouth opening. The laboratory exams revealed normal blood concentrations of

Figure 3: CT hypodense expansive lesion involving the left zygomatic arch with hyperdense lining.

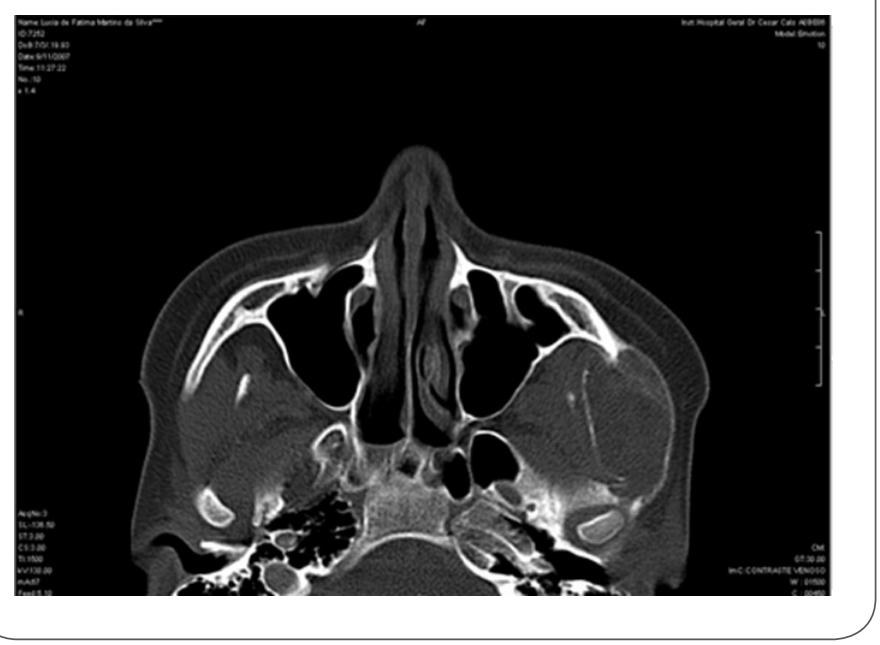

Parathormone, Calcium and Alkaline Phosphatase, which suggested a normal physiologic bone metabolism pattern. An incisional biopsy procedure was performed and the histopatological findings were consistent with $A B C$.

Definitive surgical treatment was performed through preauricular approach with superior and anterior extension (figure 4). Final histological examination revealed blood collections surrounded by connective tissue lining, which showed giant multinucleated cells along with reactive bone formation, conclusive of $A B C$ (figure 5). Clinical postoperative examination after 30 days showed facial symmetry, minimal scar and a $40 \mathrm{~mm}$ mouth opening. CT scan revealed complete removal of the lesion in the left zygomatic arch.

The patient is under regular follow-up and two years after the procedure. There is no clinical evi- dence of recurrence. Facial CT scans were taken regularly in periods of 6 months and there is also no radiological evidence of recurrence. Normal range of mouth opening, facial contour and fa-

Figure 4: Intraoperative view. The lesion was exposed and resected through pre-auricular approach with antero-superior extension.

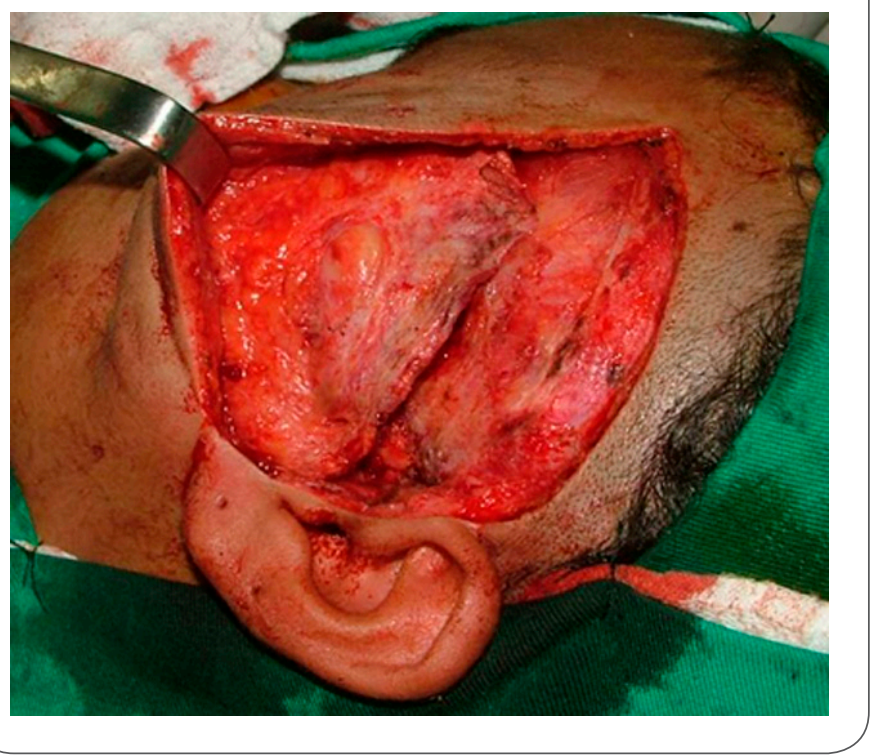

Figure 5: 400 X HE. Periphery of a cavity filled with blood that realize multinucleated giant osteoclasts-like cells involved into a fibrous stroma consisting of fibroblastlike spindle mononuclear cells.

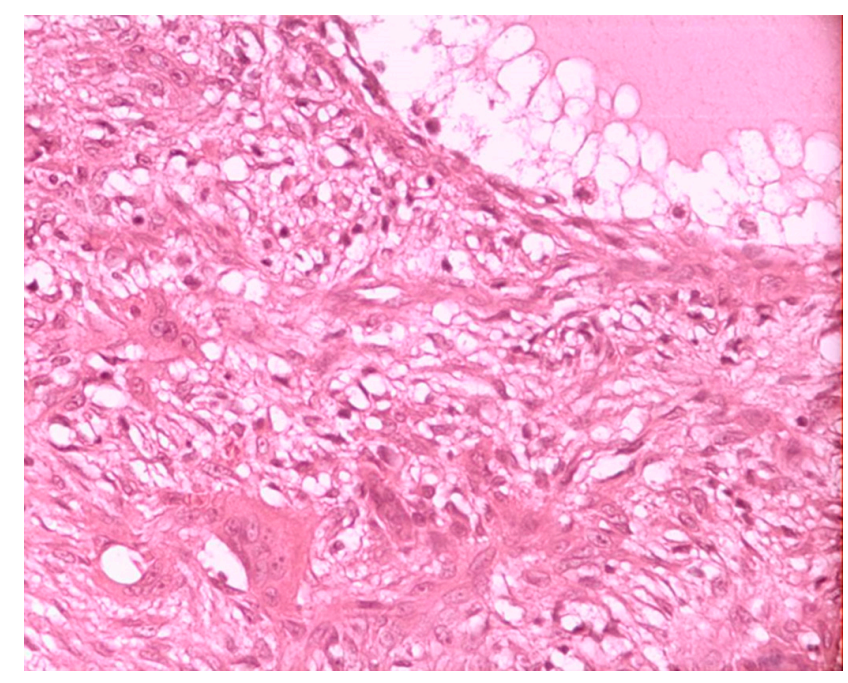


cial expressions are all well preserved (figures 6, 7 and 8).

Figure 6: Post operative clinical photograph 2 years after treatment, showing facial symmetry and preserved facial expression.

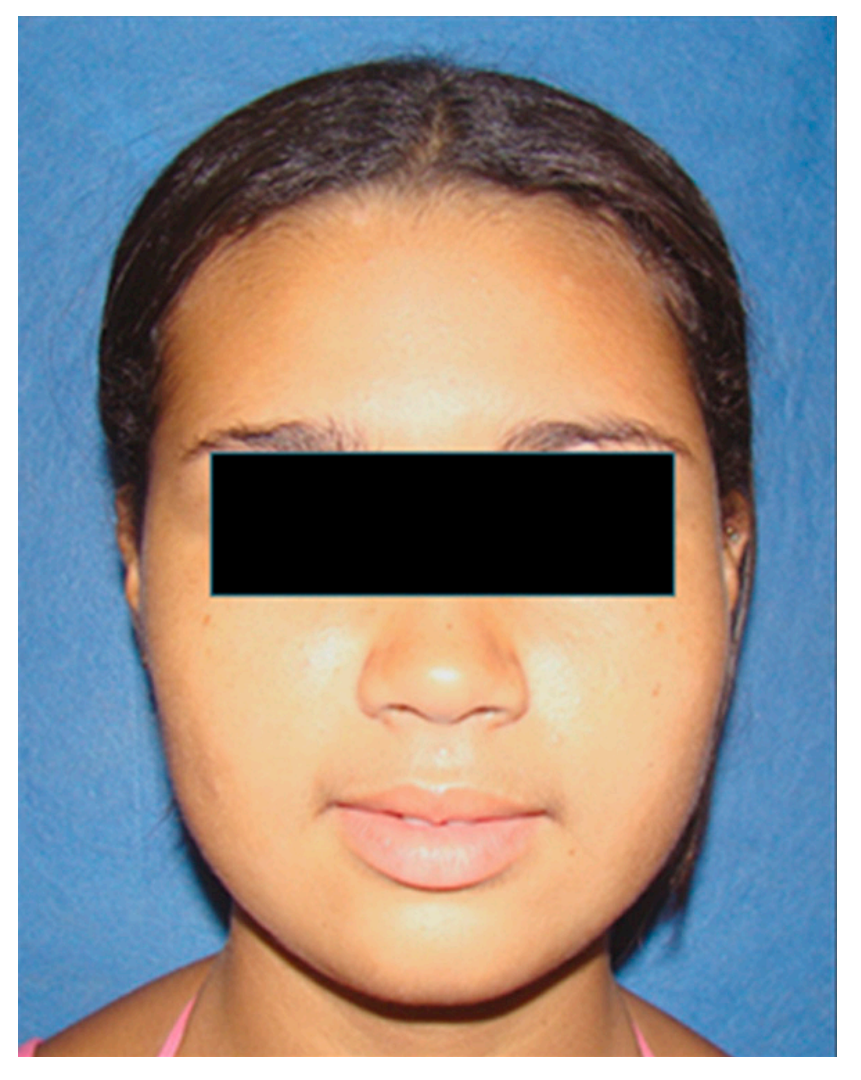

Figure 7: Post operative mouth opening 2 years after treatment, showing a $40 \mathrm{~mm}$ normal mouth opening.

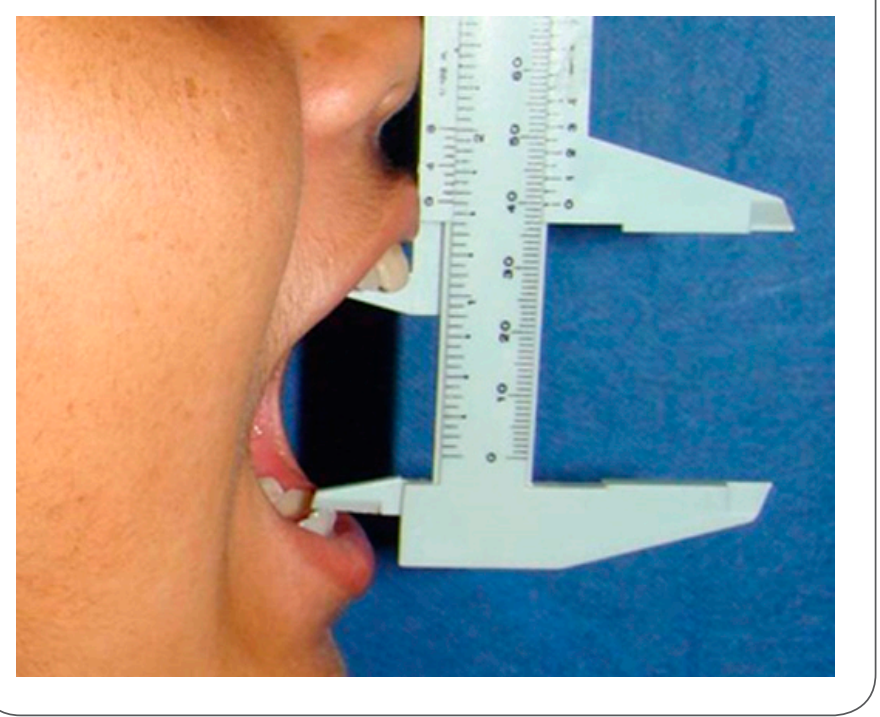

Figure 8: Final $C T$, showing absence of the left zygomatic arch lesion and no signals of recurrence.

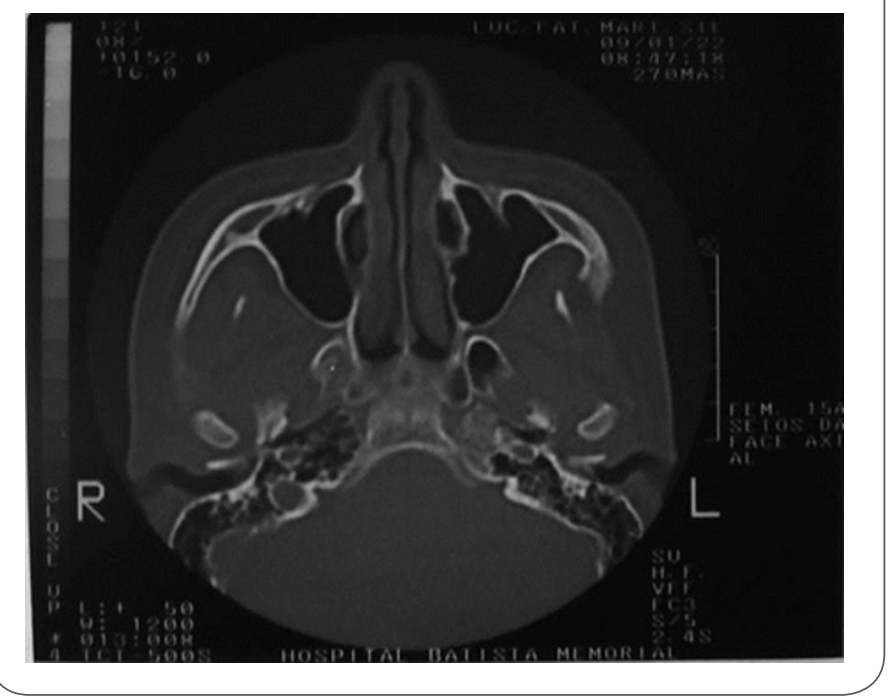

\section{Discussion}

$A B C$ etiology is still unknown. It may be a lesion of primary origin or it may develop in preexisting giant cells lesion, osteoblastoma, hyperparathyroidism brown tumor, fibrous dysplasia and osteosarcoma [11]. It is supposed that in primary origin cases some haemodynamic disorders, intraosseous vascular phenomena and arteriovenous malformation occur, leading to high intraosseous venous pressure with vascular expansion, resulting in bone resorption and replacement by connective tissue and ostheoid, which indicates reactional nature of the lesion [5]. A traumatic event may also lead to such events [12]. Cromosomal alterations of the segments $17 p$ and $16 q$ suggest a neoplastic origin [13]. However, in this patient, none of these etiologies could be determined as causative.

Long, short and tubular bones, pelvis and vertebral bodies are commonly affected. This case reports zygomatic and temporal bone involvement and our patient was a female in her second decade of life as shown to be common in other studies [6, 7]. The most commonly involved site in the oral and maxillofacial complex is the 
mandibular ascending ramus, followed by maxilla. The commitment of other bones of the head and neck is considered rare, specially the zygomatic arch $[9,14,15]$.

Clinically $A B C$ manifests as swelling of firm consistency, progressive and expansile with associated pain. When in the maxilla or mandible, the change of occlusion and tooth displacement are common clinical findings. Limitation of mouth opening as a result of mechanical impaction bone, as described here, is not a rare clinical finding [7]. Its biological behavior is variable, however, often shows rapid growth and local aggressiveness [5]. Diffuse aggressiveness with rapid destruction of adjacent tissues and structures and involvement of vital structures is a rare finding $[8,9]$ In our case, the lesion was limited to the bony anatomy, without the involvement of important structures and showed no evidence of local aggressiveness.

$A B C$ radiographycally presents as a radiolucent unicystic, uni or multilocular lesion with soap bubble or honeycomb appearance. It causes expansion, perforation or destruction of cortical bone and may show periosteal reaction with reactionary bony formation and peripheral sclerotic bone formation [3]. Differential diagnosis includes ameloblastoma, myxoma, central giant-cell lesion, hyperparathyroidism brown tumor, odontogenic cysts and bone venous malformation [16]. CT and Magnetic Resonance Imaging (MRI) enable the delineation of the margins of the lesion and its septa, as well as association with adjacent structures [3, $4,6]$. MRI can also be useful to assess if there is any perilesional edema or extraosseous soft tissue spread [6].

Histopathological analysis of a tissue sample exhibits microscopic blood-filled cavities, circumscribed by fibrous connective tissue, consisting of spindle-shaped "fibroblast-like" and giant "osteoclast-like" multinucleated cells, plus reactionary bone or irregular osteoid [17, 18]. Our findings were similar.
Several treatment modalities have been proposed for the $A B C$. These include monitoring and long-term observation which resulted in involution of lesion [19], percutaneous fibrosant agent injections [20], intra- lesional injections of calcitonin, which has inhibitory effect on osteoclastic activity and osteoinductive properties, in combination with corticosteroid injections that has angiostatic and inhibitory effect on fibroblasts. However, this treatment generally lasts for a long period of time marked with multiple repetitions of injections and has unpredictable results [21]. Cryotherapy and RT were also reported and used as an adjunct to surgical curettage to reduce the recurrence rate. However, although RT has been shown as an effective treatment modality for the $A B C$, it was abandoned due to its high potential for sarcomatous degeneration [22].

The ablative surgery is the most described. The length of the procedure depends on the size and location of the lesion. Reports of curettage and bone grafting are also found, however are associated with high recurrence rates and present with risks of massive intraoperative bleeding [3]. Embolization prior to surgical manipulation is a mean to prevent bleeding and interferes with the course of the injury, since it promotes regression of soft tissue, sclerosis and reactive bone formation $[9,23]$. In this case, embolization was not done as image revealed that there was no vascular involvement or major nutrient artery involving the tumor.

Complete resection is the surgical treatment modality that is considered more effective and associated with least recurrence $[3,7,10,15,16]$. Some authors feel that this radical surgical excision should be restricted to extensive lesions that occupy the affected bone totally and to recurrent lesions due to the severe morbidity of the procedure $[20,24]$. The choice of resective surgical approach for this case was based on the wide extent of the lesion and the total involvement of the left zygomatic arch. Furthermore, it is known that the recurrence rate 
is directly related to previous incomplete resection and simple curettage may result in recurrence in 50 $\%$ of cases [5]. The type of surgical access performed is related to fewer complications and reduced morbidity [25].

Despite there are different types of treatment for the $A B C$, there is a tendency to choose the total resection with a safety margin that allows proper treatment and reduces the chance of recurrence. Thus, surgical resection proved to be a viable treatment alternative, once the patient is in the postoperative period of two years and there is no clinical or imaginological evidence of recurrence and the functionality of the stomatognathic system is maintained.

\section{References}

1. Jaffe $H \mathrm{~L}$, Lichtenstein L. Solitary unicameral bone cyst with emphasis on the roentgen picture: the pathologic appearance and the pathogenesis. Arch Surg 1942; 44:1004

2. Boyd RC. Aneurysmal bone cysts of the jaws. Br Oral Surg 19781979; 16:248.

3. Struthers PJ, Shear M. Aneurysmal bone cysts of the jaws (II) pathogenesis. Int J Oral Surg 1984; 13:92.

4. Shafer WG, Hine MK, Levy BM. A Textbook of Oral Pathology. 4th ed. Philadelphia: WB Saunders; 1983.

5. Lichtenstein L. Aneurysmal bone cyst: observations on fifty cases. Am J Bone Joint Surg 1957; 39:873-882.

6. Lerant G, Ivanyi E, Toth E, Levai A, Godeny M. Aneurysmal bone cyst of the zygomatic arch: a case report. Clin Imaging 2013; 37(5):957-61.

7. Motamedi MH, Yazdi E. Aneurysmal bone cysts of the jaws: Analysis of 11 cases. J Oral Maxillofac Surg 1994; 52:471-475.

8. Hardee OS, Whear NM, Morgan PR. Aneurysmal bone cyst of the maxilla - an association with tooth resorption. J Craniomaxilofac Surg 1992; 20:266-269.

9. Page EL, Glenn EP. Aneurysmal bone cyst of the zygomatic arch. Head \& Neck 1994; 594-597.

10. Kumar VV, Malik NA, Kumar DB. Treatment of large recurrent aneurysmal bone cysts of mandible: transosseous intralesional embolization as an adjunct to resection. Int J Oral Maxillofac Surg 2009; 38:671-676.

11. Levy WM, Miller AS, Bonakdarpour A, Aegerter E. Aneurysmal bone cyst secondary to other osseous lesions. Report of 57 cases. Am J Clin Pathol 1975; 63:1-8.

12. Tai YT, Yen PC, Chou EK. Aneurysm bone cyst presented as a zygomatic mass after facial trauma. J Trauma 2011; 70(4):E74.

13. Althof PA, Ohmori K, Zhou M, Bailey JM, Bridge RS, Nelson M, Neff JR, Bridge JA. Cytogenetic and molecular cytogenetic findings in 43 aneurysmal bone cysts: aberrations of $17 p$ mapped to $17 p 13.2$ by fluorescence in situ hybridization. Mod Pathol 2004; 17: 518-525.

14. Winters V, Schraepen T, Geusens E, Vanwijck R, Broeckx. Aneurysmal bone cyst of the zygomatic arch. J Belge Radiol 1998; 81(1):7-8.

15. Eveson JW, Moos KF, MacDonald DG. Aneurysmal bone cyst of the zygomatic arch. Br J Oral Surg 1978; 15(3):259-64.

16. Kiattavorncharoen $S$, Joos $U$, Brinkschmidt C, Werkmeister R. Aneurysmal bone cyst of the mandible: a case report. Int J Oral Maxillofac Surg 2003; 32:419-422.

17. Jundt G. Aneurysmal Bone Cyst. In: World Health Organization Classification of Tumours Pathology and Genetics os Head and Neck Tumours. Barnes L (Editor). Lyon: IARC Press; 20005. p326.

18. Ettl T, Stander S, Schwartz S, Reichert TE, Driemel O. Recurrent aneurysmal bone cyst of the mandibular condyle with soft tissue extension. Int J Oral Maxillofac Surg 2009; 38:6. 
19. Hernandez GA, Castro A, Castro G, Amador E. Aneurysmal bone cyst versus hemangioma of the mandible. Report of a long-term follow-up of a self-limiting case. Oral Surg Oral Med Oral Pathol 1973; 76:790-796.

20. Adamsbaum C, Mascard E, Guinebre-Tiere JM, Kalifa G, Dubousset J. Intra-lesional Ethibloc injection in primary aneurysmal bone cysts: an efficient and safe treatment. Skeletal Radiologyn 2003; 32: 559-566.

21. Gladden Jr. ML, Gillingham BL, Hennrikus W. Aneurysmal bone cyst of the first cervical vertebrae in a child treated with percutaneous intralesional injection of calcitonin and methylprednisolone. A case report. Spine 2000; 25:527-530.

22. Rapidis AD, Vallianatou D, Apostolidis C, Lagogiannis G. Large lytic lesion of the ascending ramus, the condyle and the infratemporal region. J Oral Maxillofac Surg 2004; 62:996-1001.

23. Cory DA, Fritsch AS, Cohen MD, Mail JT, Holden RW, Scott JÁ, De Rosa GP. Aneurysmal bone cysts: imaging findings and embolotherapy. Am J Roentgenol 1989; 153:369-373.

24. Campanacci M, Capanna R, Picci P. Unicameral and aneurysmal bone cysts. Clin Orthop 1986; 204:25-36.

25. Al-Kayat A, Bramley PA. A modified pre-auricular approach to the temporomandibular joint and malar arch. Br J Oral Maxillofac Surg 1979; 17:91.

\section{Comment on this article:}

\section{$f(B)$ in $8+S P$}
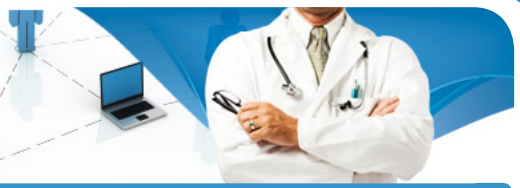

http://medicalia.org/

Where Doctors exchange clinical experiences, review their cases and share clinical knowledge. You can also access lots of medical publications for free. Join Now!

\section{Publish with iMedPub}

http://www.imed.pub

International Archives of Medicine is an open access journal publishing articles encompassing all aspects of medical science and clinical practice. IAM is considered a megajournal with independent sections on all areas of medicine. IAM is a really international journal with authors and board members from all around the world. The journal is widely indexed and classified Q1 in category Medicine. 